\title{
FINITE ELEMENT APPROXIMATION OF SOME INDEFINITE ELLIPTIC PROBLEMS
}

\author{
I. Gapuzzo Dolcetta $\left({ }^{1}\right)-$ S. Finzi Vita $\left({ }^{1}\right)$
}

Published in «Calcolo» $\cdot$ vol. $25 \cdot$ n. 4-1988

Pag. 390

$$
\begin{gathered}
\text { ERRATA } \\
\sum_{j \in s} A_{i j} u_{j}=-\sum_{j \in s} A_{i j} \sigma=\sum_{j \in s} A_{i j} \sigma
\end{gathered}
$$

that is

$$
\sum_{j \in s} A_{i j}\left(\sigma-u_{j}\right)=0
$$

since $A_{i j} \leqslant 0$ and $u_{j}<\sigma$ for $j \in S$, we get $A_{i j}=0$ for any $j \in S$, when $i \in S$. Then, after a rearrangement of its rows and columns, we can decompose $\mathrm{A}$ as follows:

\section{CORRIGE}

$$
\sum_{\mathrm{j} \notin \mathrm{s}} \mathrm{A}_{\mathrm{ij}} \mathrm{u}_{\mathrm{j}}=-\sum_{\mathrm{j} \in \mathrm{s}} \mathrm{A}_{\mathrm{ij}} \sigma=\sum_{\mathrm{j} \notin \mathrm{s}} \mathrm{A}_{\mathrm{ij}} \sigma
$$

that is

$$
\sum_{j \notin s} A_{i j}\left(\sigma-u_{j}\right)=0 ;
$$

since $A_{i j} \leqslant 0$ and $u_{j}<\sigma$ for $j \notin S$, we get $A_{i j}=0$ for any $j \notin S$, when $i \in S$. Then, after a rearrangement of its rows and columns, we can decompose $A$ as follows: 